\title{
The Relationship Between Interpersonal Approaches of Thesis Supervisors and Graduate Student Satisfaction
}

\author{
Dalal M. Aldosari ${ }^{1}$ \& Ali S. Ibrahim ${ }^{1}$ \\ ${ }^{1}$ College of Education, United Arab Emirates University, Al Ain, United Arab Emirates \\ Correspondence: Dalal M. Aldosari, College of Education, United Arab Emirates University, Al Ain, Maqam, \\ United Arab Emirates.
}

Received: April 29, 2019

doi:10.5539/ies.v12n10p96
Accepted: July 9, 2019 Online Published: September 29, 2019

URL: https://doi.org/10.5539/ies.v12n10p96

\begin{abstract}
The purpose of this explanatory mixed method study is to describe students' perceptions of the thesis supervision approaches used, their satisfaction with these approaches, and whether their satisfaction differed based on students' gender, degree sought, and concentration. The study comprised two parts. First, a questionnaire was distributed to all graduate students who had written a thesis/dissertation during 2015-2017 ( N=213) at one of the universities in the United Arab Emirates. Second, a group of students from among those mentioned above $(\mathrm{N}=16)$ were interviewed. The study revealed that the most commonly used approach by the supervisors was the collaborative interpersonal approach and the least used one was the directive informational approach. There was no significant difference according to the degree sought and concentration. However, when it came to gender, female students believed that the supervisors had used the collaborative approach more than the male students. Overall, graduate students were satisfied with their supervisors' approaches, while some were highly satisfied. The findings indicated a pattern where the more collaborative the supervisor was, the more satisfied the student became and the more the supervisor used the non-directive interpersonal approach, the less satisfied the students became. The study recommends that faculty supervisors attend to the various needs and preferences of their students and be ready to shift away from their preferred approach to suit the diverse needs and abilities of their students.
\end{abstract}

Keywords: dissertation, graduate student, interpersonal approach, student satisfaction, supervision, thesis

\section{Introduction}

Thesis writing is the last stage in achieving a graduate degree and is the pinnacle of graduate studies, as the process helps develop vital research skills (Ho, Wong, \& Wong, 2010; Ylijoki, 2001). Graduate student thesis completion can refine research skills and enhance critical/reasoning capabilities; thus, the absence of a thesis could weaken students' graduate research abilities (Drennan \& Clarke, 2009). However, Ylijoki (2001) found that the challenging process of completing the thesis also contributed to student anxiety, prolonged the time until graduation, and even resulted in students' withdrawal from graduate studies.

A crucial factor that determines how successfully students navigate the thesis writing process challenge is their relationship with their supervisors. Students are aware of the supervisor's importance in achieving their degrees (Erichsen, Bolliger, \& Halupa, 2014; McAlpine \& McKinnon, 2013). Research by de Kleijn, Meijer, Pilot, \& Brekelmans (2014) established that students identified the relationship with their thesis supervisor as a key feature in the research supervision process.

Though some supervisors may prefer to maintain a formal relationship with their students, many often become personally involved in their students' theses/dissertations. Supervisors are important for maintaining student satisfaction (de Kleijn, Mainhard, Meijer, Pilot, \& Brekelmans, 2012). Supervisors' communication and support are positively correlated with students' academic performance (Ismail, Jui, Sham, Faqih, \& Abdullah, 2015). However, students become dissatisfied when the supervision relationship lacks continuous communication, time spent together, and timely feedback (Abo-Daf, 2002; Alawi, Jabr, \& AboSamra, 2008; Shatnawi, 2006). Therefore, maintaining a productive and positive relationship is a key factor in preventing graduate student dissatisfaction and reducing graduate program withdrawal rates (Parker-Jenkins, 2018).

Many efforts have been made to classify the different types of supervisor-supervisee relationships into different approaches and models of supervision (McCallin \& Nayar, 2012). In this study, we adopt Glickman, Gordon, and 
Ross-Gordon's (2013) three main interpersonal approaches: directive, collaborative, and non-directive, which were extracted from three main philosophies, namely essentialism, experimentalism, and existentialism. These approaches were adopted to investigate the relationship between graduate student satisfaction and supervisor interpersonal approach in a government-run university in the United Arab Emirates (UAE).

\section{Conceptual Framework}

Supervision is a personal and professional relationship whereby an experienced faculty member acts as a student's guide, facilitator, role model, and informer. A supervisor provides the supervisee with knowledge, advice, counseling, challenges, and support in the supervisee's journey toward a particular profession (Johnson, 2016). According to Wisker (2012, pp. 40-41), the supervision of graduate students is "a professional relationship ... that focuses on development and training... Students at all levels need guidance, modeling and managing so that they can start to develop as independent researchers". Every supervisor has his/her own interpersonal approach in dealing with his/her students. Glickman et al. (2013, p. 90) noted that the interpersonal approach "is a range of interpersonal behaviors available to a supervisor who is working with individuals and groups". Lee (2008) observed that supervisors who are aware of the strengths and weaknesses of supervision approaches are more likely to enjoy and benefit from the supervision experience.

As discussed in Glickman et al. (2013), essentialists believe that knowledge, truth, and reality exist outside of humans and that knowledge does not change. The purpose of education is to train the mind to think logically (Glickman et al., 2013). Bagley founded this philosophy in 1938 (Glickman et al., 2013). Essentialism advocates that there is essential subjects/knowledge that students should learn, and the educator is the main source of this knowledge (Kessinger, 2011). Thus, from the essentialist perspective, the supervisor is the expert who transfers knowledge to a student or trainee. As students follow the supervisor's directions, they grow closer to becoming good learners (Glickman et al., 2013).

Essentialism coincides with the first main interpersonal supervisory approach, the directive approach. The directive approach is divided into two types: directive control and directive informational. Directive control means that the supervisor directs the student by standardizing specific time tables and criteria that ensure the expected results. The supervisor also guides the student by explaining the positive and negative consequences of his/her actions. In the directive informational approach, the supervisor directs the student to choose from the available alternatives. In the directive approaches (control or informational), the supervisor is the source of knowledge, has the power and responsibility, and s/he is the one who makes the decisions, but the degree of freedom in the first approach is far less than in the second (Glickman et al., 2013).

Experimentalism emphasizes that reality, knowledge, and truth are not absolutes and are instead continuously changing and updating (Glickman et al., 2013). Experimentalists believe that people are born with limitless possibilities for development and growth. Therefore, the traditional educator-learner relationship where the educator is the only source of knowledge is not sufficient for experimentalists (Elias \& Merriam, 1995). Experimentalism represents a collaborative interpersonal approach where the supervisor works democratically with the student to test old hypotheses and try new ones (Glickman et al., 2013). In the collaborative interpersonal approach, the supervisor and student share equal power, make joint decisions, and bear equal responsibility (Glickman et al., 2013).

Existentialism asserts that humans are the source of reality, truth, and knowledge. It emphasizes that there is no absolute knowledge or logic because this will prevent humans from discovering existence and then it will keep them ignorant (Glickman et al., 2013). Existentialism encourages individuals to create their own meaning from the world around them and to engage in self-discovery (Glickman et al., 2013; Koirala, 2011). Thus, supervision in existentialism means that the supervisor helps the student explore his or her own capabilities to make decisions freely. Supervisors are facilitators and offer help when necessary (Glickman et al., 2013). The non-directive interpersonal approach to supervision is extracted from this philosophy. It means that the student leads the supervision process, has the responsibility, and makes decisions. The supervisor's role facilitates autonomous learning so that the student can develop acceptable results (Glickman et al., 2013; Koirala, 2011). Figure 1 illustrates the different philosophies and Glickman et al.'s (2013) approaches to supervisions that guide this study. 


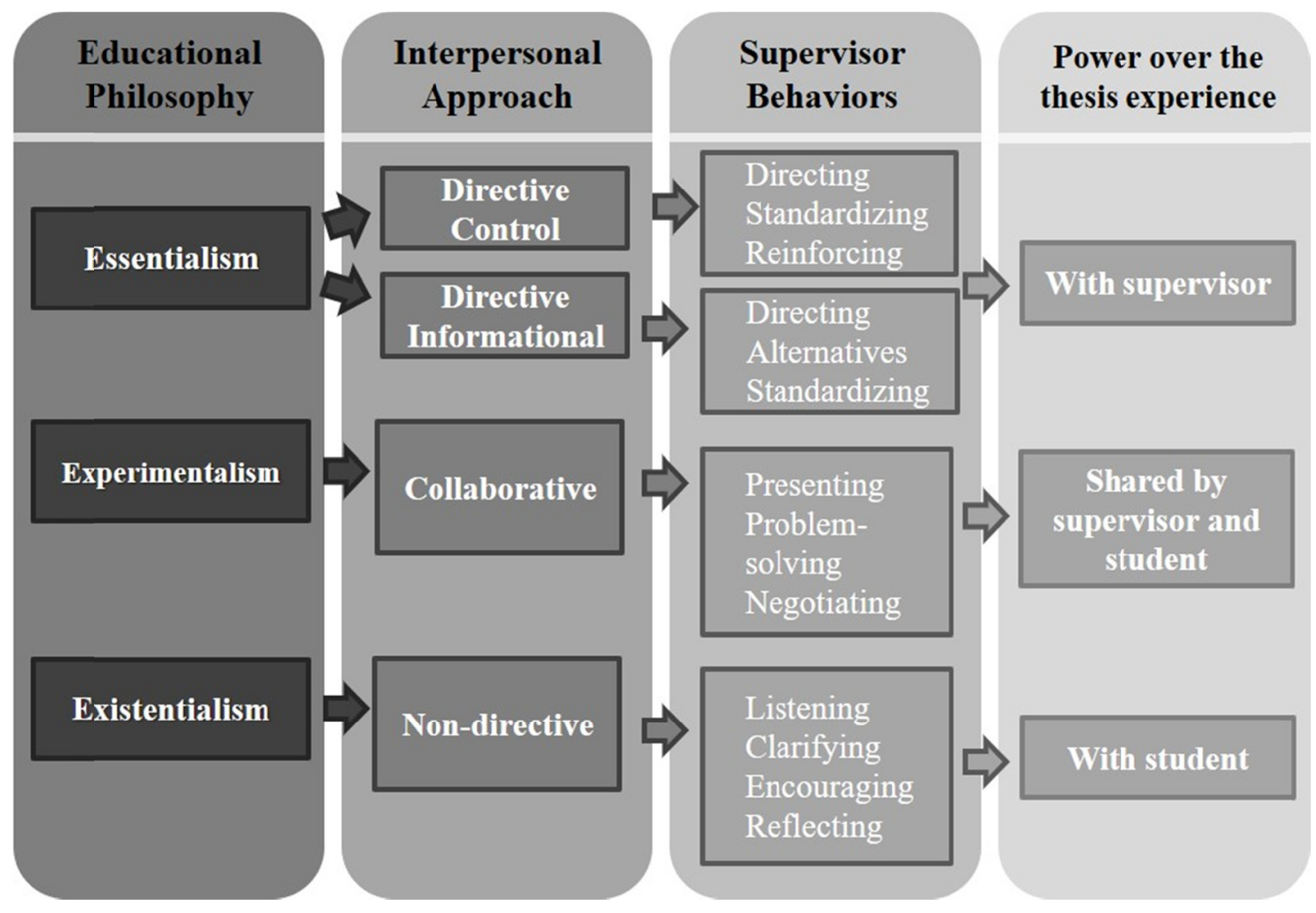

Figure 1. Conceptual framework

\section{Literature Review}

There are a dearth of previous studies related to the above approaches in the context of studying graduate students because their approaches were mostly used to describe supervisor-teacher relationships; therefore, this is likely one of the first studies that utilizes the approaches framed by Glickman et al. (2013) to explain supervisor-graduate student relationships. However, there are many studies on the supervisor-graduate student relationship, which we discuss in detail in the following subsections.

\subsection{Studies on the Approaches Derived from the Literature}

Lee (2007) conducted a literature review to list five supervisory models. Then, he conducted a study in 2008 by implementing the five supervisory models - functional, enculturation, critical thinking, emancipation, and developing a quality relationship. The study showed that supervisors tend to use the functional approach (wherein the supervisor helps the doctoral student acquire reasonable progress throughout the research phases and agrees on the importance of student obedience) and one other approach.

Acker, Hill, and Black (1994) outlined two supervision models: the technical rationality model and the negotiated order model. In the technical rationality model, supervision priority was given to procedure or technique issues whereas the negotiated order model assumed that supervision was "a process open to negotiation and change" (Acker et al., 1994, p. 483). The technical rationality model must be carried out in predictable steps that would structure the students' growth in the research field, leaving them as passive participants. In the negotiated order model, the students and supervisors shared responsibilities, and this model prepares students to be active participants in negotiating and understanding research. The negotiated order model more accurately describes successful social science supervision.

McCallin and Nayar (2012) also reviewed the 2000 to 2010 literature to discuss the influence of postgraduate supervision in New Zealand. They suggested that supervisors and students should have enough training to adjust to supervision changes to improve research excellence and increase doctoral degree completion rates.

\subsection{Studies on Approaches Derived from Existing Approaches}

Aguinis, Nesler, Quigley, Suk-Jae-Lee, and Tedeschi (1996) implemented French and Raven's (1959) power taxonomy (referent, coercive, expert, legitimate, and reward power) to examine the relationship between the 
supervisor's power and the students' educational outcomes. The study concluded that the expert power (i.e., when the supervisor is viewed as having special knowledge) was positively associated with the student's educational outcomes, while coercive power (i.e., when the supervisor is viewed as a potential punisher) was associated negatively with the student's educational outcomes.

Raven (2008) added informational power to the taxonomy, which means that the supervisor uses diverse and logical explanations for conducting research that the supervisee understands and accepts. Raven addressed that the effectiveness of the specific power type is dependent on the nature of the supervisor, the supervisee, and the context. He found that reward power leads to higher supervisee satisfaction and emphasized that supervisors with awareness of these power strategies are more effective supervisors.

Armstrong (2004) used known theories and approaches to investigate the influence of supervisors' cognitive styles on supervision quality. His study involved analytic (step-by-step method) and intuitive (supervisors use their feelings to act regardless of the conscious reasoning) styles. The findings showed that the more the supervisor was analytic, the more the students perceived the quality of the supervision and "achieved significantly higher grades for their dissertation" (p. 599).

\subsection{Studies Investigating Students and/or Supervisors' Perceptions}

Abdallah, Hillerinch, Romero, Topp, and Wnuk (2010) interviewed an experienced professor to identify the relationships between supervisors and students. Bartlett and Mercer's (2000) model, which is used in this study, had three approaches. The first is "creating in the kitchen," where the supervisor is the leader and has a close relationship with the supervisee. The second approach is "digging in the garden," where they do not work together, and the supervisor just offers advice to the student. The third approach is the "bush walking" approach, where the supervisor and student have equal power and a close relationship. They identified the importance of supervisors organizing communication with their students and found that the "creating in the kitchen" model was the most suitable approach. However, there is no ultimate, standardized model for all supervision processes.

Ylijoki (2001) identified the thesis writing issues from the students' perspectives. Based on the experiences of 72 Finnish students, four core cultural narratives were developed: heroic, tragic, businesslike, and penal stories (and all students subconsciously follow their own story). Each story presents a different perspective on the importance of thesis writing, the relationship between the supervisor and the student, and study problems. It is important that students recognize their narratives to improve the supervision process. Students and supervisors should hold the same narrative to enhance their relationships.

Franke and Arvidsson (2011) analyzed the different ways that supervisors advise their doctoral students and revealed two main supervision structures: research practice-oriented and research relation-oriented supervision. In research practice-oriented supervision, the supervisor and the student share mutual research practices, while research relation-oriented supervision means that the supervisor and the student lack a clear connection between their research practices. The results also showed that approximately $23.3 \%$ of the supervisors use both structures.

There is no standardized approach to be used for all graduate students' thesis or dissertation supervision. Based on the existing studies, it is difficult to determine the best practices that supervisors should rely on. However, a controlling approach is more positively related to students' grades/learning, and a positive relationship leads more to students' satisfaction (de Kleijn et al., 2012). As Parker-Jenkins (2018) noted, the supervisory relationships' expectations, roles, and boundaries must be initially expressed to avoid any misunderstanding and to encourage higher rates of thesis/dissertation completion.

\section{Statement of the Problem}

The graduate thesis assesses a student's likelihood of conducting research (Drennan \& Clarke, 2009). However, a large proportion of students exit their graduate program without completing their thesis (Gosling \& Noordam, 2011). Improving the supervision process can improve student satisfaction and increase student retention rates. Many studies have emphasized the importance of the supervisor-student relationship and its impact on students' educational outcomes and satisfaction (e.g., Aguinis et al., 1996; de Kleijn et al., 2014; Erichsen et al., 2014; Ismail et al., 2015).

The key role of the supervisor in postgraduate studies makes it a pertinent subject for research. Despite its importance, however, little research has been conducted to examine supervision in the context of the UAE. Hence, the researchers carried out a preliminary study to explore the situation in one UAE university. The study drew on responses from six graduate student interviews (four master and two PhD graduates). The early small-scale study provided interesting preliminary insights. A major finding was that some supervisors were controlling and did not give students the freedom to make important decisions, such as topic selection and methodology. Students reported 
that some supervisors reportedly used coercive power. As one $\mathrm{PhD}$ student described her interaction with her supervisor: "His attitude was angry... the attitude was very bad, not only with me." Students' concerns about not receiving effective feedback were also raised repeatedly, with one student saying, "There was no proper guidance regarding the methodology." The lack of timely feedback delayed the students' completion of their thesis. One student reported saying, "Writing my thesis took a very long time ... If he had given me feedback about every chapter from the beginning, I would have finished my thesis earlier."

These preliminary conversations offered insight into the supervision process, but it is important to more fully investigate supervision approaches. By studying these approaches, we can gain a deeper understanding of how they may affect students' satisfaction, particularly in the UAE. This study also adds to the literature on supervision and the supervisor-student relationship in higher education in general and in the UAE, particularly.

\section{Research Questions}

This study was guided by the following research questions:

1) What are the supervisory approaches used by faculty members and how satisfied are graduate students with these approaches?

2) Is there a relationship between supervision approaches and student satisfaction? Is there a significant difference in the relationship between graduate student satisfaction and supervisor interpersonal approaches according to the gender, level of education (master's or PhD), and concentration (Sciences or Arts) of the students?

3) How do students perceive the relationship between the supervisors' interpersonal approaches and their satisfaction with using these approaches?

\section{Methodology}

\subsection{Study Design}

This study used an explanatory mixed method design, by first collecting quantitative data and then collecting/using qualitative data to better understand the quantitative results (Gay, Mills, \& Airasian, 2011). The quantitative data provided information on a large sample of graduate students concerning their opinions of their supervisors' approaches and their satisfaction, whereas the qualitative data provided more in-depth data and greater details on their experiences.

\subsection{Instruments}

We used semi-structured interviews and a closed questionnaire. The questionnaire addressed the first and second research questions and included two sections: demographic data/supervisory practices and graduate student satisfaction. The demographic data covered gender (male or female), level of education (master's or PhD), college (Arts or Sciences), and status (already graduated or about to graduate). The supervisory practice questions covered six main thesis/dissertation writing phases: topic selection, development of research problem, framing of the literature review, research method decisions, feedback process, and writing the discussion chapter. A final question gauged the supervisor's overall approach and the student's overall satisfaction level. For questions about the approaches used, the students selected from four choices: directive control, directive informational, collaborative, and non-directive. For the sub-questions on satisfaction, a six-level satisfaction scale was used, ranging from not satisfied at all $=1$ to totally satisfied $=6$.

Next, semi-structured interviews were conducted to address the third research question. These interviews allowed the researchers to ask pre-prepared questions and to improvise as needed (Wengraf, 2001). The semi-structured interviews covered demographic data and supervisory practices and included questions similar to those in the questionnaire but with different wording.

\subsection{Validity and Reliability}

Six experienced academicians reviewed the questionnaire and interview questions to determine the instruments' validity. We made minor question adjustments based on their advice (which largely focused on language). To measure the instrument reliability, the test-retest method was used by distributing the questionnaire to a group of 15 graduate students who were not included in the research sample. The researcher subsequently redistributed it after 10 to 14 days to the same group. Then, the Pearson coefficient was used to measure the correlation between their pre-test and post-test responses. The scores were very high ( 0.831 to 0.960$)$, revealing that there was a high correlation between the first and second administrations and that this part of the questionnaire was highly reliable. Cronbach's alpha was then used to test the satisfaction scale. The scores were very high (0.951 and 0.958$)$, indicating that the instruments were reliable. 


\subsection{Population and Sample}

The target population included both master's and $\mathrm{PhD}$ students, who had written or were about to finish writing their thesis/dissertation between 2015 and 2017 at one UAE university $(\mathrm{N}=213)$. There were 175 master's and 38 $\mathrm{PhD}$ graduates. The researcher intentionally targeted this group as they were more likely to remember their thesis/dissertation supervision experience than those who had graduated earlier or those who had not yet arrived at the final stages of their thesis/dissertation.

The questionnaire was sent to all graduated and enrolled graduate students. A total of 124 participants completed the questionnaire, indicating a $58.2 \%$ response rate. The sample consisted of 45 males $(36.3 \%)$ and 79 females (63.7\%), with the majority enrolled in the sciences-related colleges (91 students), compared to a smaller number in the humanities-related colleges ( 33 students). Of the 124 respondents, 105 were master's students who had written or were in the process of writing a thesis; the remaining were $\mathrm{PhD}$ students. Most of the participants $(61.3 \%)$ had already graduated, whereas $38.7 \%$ were about to graduate.

The interview participants were selected from the quantitative sample based on their willingness to be interviewed. The sample comprised 16 students: 2 males and 14 females, 11 master's students and $5 \mathrm{PhD}$ candidates, with half in the humanities-related colleges and half in the sciences-related colleges.

\subsection{Procedures}

The researchers first obtained the proper ethical institutional approval. Then, the researchers contacted the university's registration department to obtain the potential participants' contact information.

Next, an electronic questionnaire link with an invitation to participate was sent to all 213 participants. The electronic questionnaire required the participants' informed consent, which participants electronically confirmed before beginning the questionnaire.

Willing participants from the quantitative sample who provided their contact information were invited to sit for a semi-structured interview. The average duration of each interview was from 12 to 35 minutes. Most interviews were face-to-face and recorded, while a few were phone interviews in cases where the alumni were in distant cities. In such cases, notes were taken during the interview. For the face-to-face interviews, participants were asked to sign the informed consent form and were given a copy. For the phone interviews, the informed consent form was sent to participants prior to the interview. All interviews were then transcribed.

\subsection{Data Analysis}

For the quantitative study, the researcher used percentages to identify the most common supervision approaches. Students' satisfaction levels were assessed using a six-point Likert-type scale, ranging from not satisfied at all $=1$ to totally satisfied $=6$, and the means, medians, modes, and standard deviations were then calculated to ascertain the overall satisfaction level. SPSS software was used to extract these frequencies and to analyze the data.

To identify the relationship between the supervision approach used and students' satisfaction level, One-Way ANOVA and post hoc Tukey tests were used to analyze each question, with supervision approach as the independent variable and student satisfaction as the dependent variable. The Mann-Whitney $U$ test was used to identify the differences in the relationship between graduate students' satisfaction and supervisors' interpersonal approach according to the level of education, gender, and concentration.

The qualitative data were extracted from verbatim interview transcriptions. A thematic analysis was then conducted to examine the students' perceptions of their supervision experience during the thesis/dissertation writing process.

\section{Results}

\subsection{Question One Results}

\subsubsection{Supervisory Approaches}

Most students (57.3\%) reported that their supervisors most often used the collaborative approach, followed by the non-directive approach (17.7\%), the directive control approach (13.7\%), and the directive informational approach $(11.3 \%)$. Table 1 displays the results. 
Table 1. Supervision approaches used in percentages (\%)

\begin{tabular}{lcccc}
\hline & Directive Control & Directive Informational & Collaborative & Non-directive \\
\hline 1. Research topic selection & 21.8 & 16.9 & 32.3 & 29.0 \\
2. Research problem formulation & 20.2 & 11.3 & 51.6 & 16.9 \\
3. Literature review framing & 13.7 & 10.5 & 37.9 & 37.9 \\
4. Research methodology decisions & 21.0 & 14.5 & 46.0 & 18.5 \\
5. Providing feedback & 11.3 & 21.8 & 52.4 & 14.5 \\
6. Writing the discussion chapter & 9.7 & 12.9 & 54.8 & 22.6 \\
7. Overall approach & 13.7 & 11.3 & 57.3 & 17.7 \\
\hline
\end{tabular}

\subsubsection{Student Satisfaction}

A six-level scale was used to assess satisfaction, with the following breakdown: "not satisfied at all" (M=1-1.83), "dissatisfied" $(M=1.84-2.66)$, "somewhat unsatisfied" $(M=2.67-3.49)$, "somewhat satisfied" $(M=3.5-4.32)$, "satisfied" ( $(\mathrm{M}=4.33-5.15)$, and "totally satisfied" $(\mathrm{M}=5.16-6)$. The mean values ranged from 5.01 to 5.31, indicating that students generally ranged from "satisfied" to "totally satisfied" with their supervisor's interpersonal approach. They were "totally satisfied" with research topic selection $(M=5.31)$ and research methodology decisions $(M=5.18)$, and they were "satisfied" with the remaining phases. The students were most satisfied with research topic selection and least satisfied with the feedback provided $(\mathrm{M}=5.01)$.

\subsection{Question Two Results}

A one-way ANOVA test was conducted to check whether there was a relationship between the supervisor's interpersonal approach and the graduate student's satisfaction level. We then conducted a post hoc Tukey test to observe which approach was related to higher satisfaction levels. The ANOVA showed that there was a statistically significant relationship between the supervisor's approach and the student's satisfaction level, F (3.120) $=17.770$, $\mathrm{p}=.000$ (See Table 2). Multiple comparisons showed that the collaborative approach was positively related to students' satisfaction, while the non-directive approach was negatively related to students' satisfaction (Tables 2 and 3).

Table 2. ANOVA test of graduate students' satisfaction levels with supervisors' approaches

\begin{tabular}{lccccc}
\hline & Sum of Squares & df & Mean Squared & F & Sig. \\
\hline Between Groups & 53.503 & 3 & 17.834 & 17.770 & .000 \\
Within Groups & 120.432 & 120 & 1.004 & & \\
Total & 173.935 & 123 & & & \\
\hline
\end{tabular}

Table 3. Post Hoc Tests 6

\begin{tabular}{|c|c|c|c|c|c|c|}
\hline \multicolumn{7}{|l|}{ Multiple Comparisons } \\
\hline \multicolumn{7}{|c|}{ Dependent Variable: In general, how satisfied are you with your supervisor's approach? } \\
\hline \multicolumn{7}{|l|}{ Tukey HSD } \\
\hline \multirow{2}{*}{ (I) } & \multirow{2}{*}{$(\mathrm{J})$} & \multirow{2}{*}{ Mean Difference (I - J) } & \multirow{2}{*}{ Std. Error } & \multirow{2}{*}{ Sig. } & \multicolumn{2}{|c|}{$95 \%$ Confidence Interval } \\
\hline & & & & & Lower Bound & Upper Bound \\
\hline \multirow{4}{*}{ Directive Control } & Directive Informational & -.47059 & .36155 & .564 & -1.4126 & .4714 \\
\hline & Collaborative & $-1.11848 *$ & .27050 & .000 & -1.8232 & -.4137 \\
\hline & Non-Directive & .52941 & .32350 & .362 & -.3134 & 1.3723 \\
\hline & Directive Control & .47059 & .36155 & .564 & -.4714 & 1.4126 \\
\hline \multirow{2}{*}{ Directive Informational } & Collaborative & -.64789 & .29295 & .126 & -1.4111 & .1154 \\
\hline & Non-Directive & $1.00000^{*}$ & .34250 & .021 & .1077 & 1.8923 \\
\hline \multirow{4}{*}{ Collaborative } & Directive Control & $1.11848 *$ & .27050 & .000 & .4137 & 1.8232 \\
\hline & Directive Informational & .64789 & .29295 & .126 & -.1154 & 1.4111 \\
\hline & Non-Directive & $1.64789^{*}$ & .24445 & .000 & 1.0110 & 2.2848 \\
\hline & Directive Control & -.52941 & .32350 & .362 & -1.3723 & .3134 \\
\hline \multirow[t]{2}{*}{ Non-Directive } & Directive Informational & $-1.00000 *$ & .34250 & .021 & -1.8923 & -.1077 \\
\hline & Collaborative & $-1.64789 *$ & .24445 & .000 & -2.2848 & -1.0110 \\
\hline
\end{tabular}

*. The mean difference is significant at the 0.05 level. 
The Mann-Whitney $U$ test results indicated that there is a significant difference based on gender $(p=.019)$. Female students $(M=67.61)$ believed that supervisors used the collaborative approach more than male students $(\mathrm{M}=$ 53.52). There was no significant difference between male and female students as both groups were satisfied. There was no significant difference in the relationship between graduate student satisfaction and the supervisor's interpersonal approach according to the level of education and concentration.

\subsection{Question Three Results}

The quantitative and qualitative results are presented here to address question three. Table 4 illustrates the statistically significant relationship, if any, between the supervisor's interpersonal approach and the graduate student's satisfaction level, identifying which approach led to higher or lower students' satisfaction for each thesis/dissertation writing phase. The collaborative approach resulted in more students' satisfaction in almost all writing stages. The non-directive approach caused less satisfaction in almost all writing stages.

Table 4. Relationship between the supervisor's interpersonal approach and the graduate student's satisfaction level

\begin{tabular}{lccc}
\hline Phase & $P$ & More satisfied & Less satisfied \\
\hline Research topic selection & .427 & - & - \\
Research problem formulation & .001 & Collaborative & Directive control \\
Literature review framing & .033 & Collaborative & Non-directive \\
Research methodology decision & .000 & Collaborative & Non-directive \\
Providing feedback & .000 & Collaborative & Non-directive \\
Writing the discussion chapter & .000 & Collaborative & Non-directive \\
Overall approach & .000 & Collaborative & Non-directive \\
\hline
\end{tabular}

The qualitative results indicate that students were generally satisfied. However, most students felt more satisfied when they had discussions with and received directions from their supervisors at every phase. For example, one student said, "After several meetings, we agreed on the topic... I was really satisfied." Another student mentioned, "He is a specialist, so he knew where the problem was, he explained the idea to me and then I added to it... and I was satisfied with this."

On the other hand, students were less satisfied when their supervisors gave them complete, uninterrupted freedom. One student reported, "I had the complete freedom from my advisor to choose the topic... I wasn't satisfied completely with the way of my supervisor because I suffered too much to choose my topic." Another student added, "The discussion chapter was written by me without any guidance from the supervisor, I was led by previous studies to write it... I was not satisfied."

Thirteen of 16 participants believed that their supervisors used collaborative interpersonal approaches during their thesis/dissertation writing process. Six students stated that their supervisors always used the collaborative interpersonal approach, while three students reported that they used it in the later phases of the thesis/dissertation writing process, as they moved from the directive interpersonal approach to the collaborative interpersonal approach. On the other hand, four students stated that the supervisors had used it alongside the other three interpersonal approaches. For example, one student said, "She was directive in the beginning, and then moved to the discussion approach. I am very satisfied with her behavior." Another student declared, "It was a combination of all approaches with more of independent work from my side, and more of positive and supportive guidance from my supervisor's side, and the result was a great deal of learning."

\section{Discussion}

The results indicate that most students believed that supervisors most often use collaborative interpersonal approach and least often use directive informational approach, which might suggest either that students were aware that they had equal power with their supervisors or that the students reported on the most-recent supervision approach used. Previous studies conducted regionally at different universities showed that students held high evaluations of their supervisors' human relations (e.g., Abo-Daf, 2002; Alawi et al., 2008; Al-Sakraan, 2016), which suggests that supervisors' high human relations levels might also have contributed to students' satisfaction levels and approach evaluations and led them to conclude that they experienced collaborative interpersonal approach. It remains true that students are more satisfied when they share power with supervisors in the thesis/dissertation writing process. This confirms Acker et al.'s (1994) "negotiated order model" and Fernando and Hulse-Killacky's (2005) "attractive supervisory style" (i.e., a process based on negotiation, change, and supervisor support). The question two results indicated that the collaborative approach increases student's satisfaction; 
therefore, it is important that supervisors acknowledge and trust their graduate students' capabilities, ideas, and decisions instead of implementing their own ideas. Presenting ideas, problem solving, and negotiating solutions (Glickman et al., 2013) can be implemented to better this approach.

The results indicate that there was no significant difference in the relationship between graduate student satisfaction and supervisor interpersonal approach according to education level or study area, which corroborates previous findings (Shatnawi, 2006). However, the results indicate that there is a significant gender difference in that female students (in comparison to male students) believed that their supervisors more often used the collaborative approach. A potential explanation for this finding is that female students were more committed and thus had more discussions and meetings with their supervisors, affecting their interpersonal approach perceptions.

The qualitative data suggested that there is a relationship between the supervisor's interpersonal approach and student satisfaction in that students are more satisfied as supervisors are more collaborative (i.e., the supervisor listens, responds, is encouraging, negotiates, etc.). Conversely, students are less satisfied with the non-directive supervision approach, which is indicative of how supervisors perceive students' competency levels. These results are supported by Ibrahim (2018), who found that supervisors employ directive control or directive informational approaches due to their negative perceptions of the abilities of incoming graduate students. The current study also found that students were less satisfied when their supervisors did not offer directions, which is supported by Abdallah et al.'s (2010) argument that supervisors should offer guidance and support while also encouraging student independence.

Many studies encourage supervisors to vary their approaches depending on individual student capabilities (e.g., Abdallah et al., 2010; Acker et al., 1994; Armstrong, 2004; Fernando \& Hulse-Killacky, 2005; Lee, 2008; McCallin \& Nayar, 2012; Raven, 2008). Per Ibrahim (2018), limiting students with directions and defined choices does not help them become independent scholars. Therefore, we iterate the idea that graduate students need freedom in order to be successful scholars/practitioners.

This study focused on students' satisfaction with their supervisors' interpersonal approaches. However, it is important to note that some students might be satisfied with the supervision approach used but dissatisfied with the thesis/dissertation itself. It is important to note that different approaches are useful for different ends. For instance, Fernando and Hulse-Killacky (2005) found that only the task-oriented style, which is similar to the directive approach, was statistically significant in predicting students' self-efficacy. Therefore, when the goal is to efficiently finish the task and to promote self-efficacy, a directive approach is more suitable. A collaborative approach is more useful when the concern is student satisfaction. Student satisfaction is important but should not preclude the production of quality work. If a balance between the two objectives is reached, the chance that students will "create long-term institutional advocates" (Johnson, 2016, p. 11) will increase.

\section{Conclusion}

We found that, to achieve the best supervision process, several supervision styles must be used. We recommend that supervisors begin with the most satisfying approach, the collaborative approach, with experienced students/researchers until they can discern which approach type best suits the student. With novice students/researchers, supervisors might transition from the directive to the collaborative approach. It is also important that students begin the process by communicating their needs, preferences, and abilities so that supervisors can adapt their approaches accordingly. Ideally, supervisors should balance the three supervision approaches, depending on students' needs, abilities, and willingness. Supervisors should prepare to tailor their approach to cater to a diverse student population. Students also should constantly keep their supervisors updated on their needs, interests, preferences, and abilities. This will help them grow through the process.

\subsection{Suggestions for Further Study}

Existing studies have not identified a correlation between gender and students' supervision evaluations (e.g., Abo-Daf, 2002; Alawi et al., 2008; Shatnawi, 2006). We therefore recommend that future research should further investigate this correlation.

The scope of this study did not include age variables, which could be relevant. Some students do not proceed directly from undergraduate to graduate studies and return to undertake a master's or $\mathrm{PhD}$ after starting their career or while working in their career. Further study is needed to determine whether age has some bearing on student experience with supervisors.

\section{References}

Abdallah, F., Hillerinch, K., Romero, V., Topp, E., \& Wnuk, K. (2010). Supervision of a Master's Thesis: Analysis and Guidelines. Project Reports-Genombrottet, LTH. 
Abo-Daf, M. K. (2002). The evaluation of the university professor performance in the field of academic supervision from the perspective of postgraduate students. Journal of Reading and knowledge, 17, 15-54.

Acker, S., Hill, T., \& Black, E. (1994). Thesis supervision in the social sciences: Managed or negotiated? Higher Education, 28(4), 483-498. https://doi.org/10.1007/BF01383939

Aguinis, H., Nesler, M., Quigley, B., Suk-Jae-Lee, \& Tedeschi, J. (1996). Power Bases of Faculty Supervisors and Educational Outcomes for Graduate Students. The Journal of Higher Education, 67(3), 267-297. https://doi.org/10.2307/2943845

Alawi, H. R., Jabr, A. F., \& AboSamra, M. (2008). The views of students and graduates on whether supervision of the Master Thesis in Education possess the supervisory skills at Palestinian universities. Journal of the Association of Arab Universities for Research in Higher Education, 51, 485-526.

Al-Sakraan, A. F. (2016). Developmental vision of the role of the academic supervisor of theses, dissertations, and complementary research of postgraduate students in departments of education at Al-Imam Muhammad Ibn Saud Islamic University. Journal of Educational Sciences, 6, 15-71. https://doi.org/10.12816/0030297

Armstrong, S. J. (2004). The impact of supervisors' cognitive styles on the quality of research supervision in management education. British Journal of Educational Psychology, 74(4), 599-616. https://doi.org/10.1348/0007099042376436

Dde Kleijn, R. A., Mainhard, M. T., \& Meijer, P. C. (2013). Master's thesis projects: Student perceptions of supervisor feedback. Assessment \& Evaluation in Higher Education, 38(8), 1012-1026. https://doi.org/10.1080/02602938.2013.777690

De Kleijn, R. A., Mainhard, M. T., Meijer, P. C., Pilot, A., \& Brekelmans, M. (2012). Master's thesis supervision: Relations between perceptions of the supervisor-student relationship, final grade, perceived supervisor contribution to learning and student satisfaction. Studies in Higher Education, 37(8), 925-939. https://doi.org/10.1080/03075079.2011.556717

De Kleijn, R. A., Meijer, P. C., Pilot, A., \& Brekelmans, M. (2014). The relation between feedback perceptions and the supervisor-student relationship in master's thesis projects. Teaching in Higher Education, 19(4), 336-349. https://doi.org/10.1080/13562517.2013.860109

Drennan, J., \& Clarke, M. (2009). Coursework master's programmes: The student's experience of research and research supervision. Studies in Higher Education, 34(5), 483-500. https://doi.org/10.1080/03075070802597150

Elias, J. L., \& Merriam, S. B. (1995). Philosophical foundations of adult education. Melbourne: Krieger Publishing Co.

Erichsen, E. A., Bolliger, D. U., \& Halupa, C. (2014). Student satisfaction with graduate supervision in doctoral programs primarily delivered in distance education settings. Studies in Higher Education, 39(2), 321-338. https://doi.org/10.1080/03075079.2012.709496

Fernando, D. M., \& Hulse-Killacky, D. (2005). The relationship of supervisory styles to satisfaction with supervision and the perceived self-efficacy of master's-level counseling students. Counselor education and supervision, 44(4), 293. https://doi.org/10.1002/j.1556-6978.2005.tb01757.x

Franke, A., \& Arvidsson, B. (2011). Research supervisors' different ways of experiencing supervision of doctoral students. Studies in Higher Education, 36(1), 7-19. https://doi.org/10.1080/03075070903402151

Gay, L. R., Mills, G. E., \& Airasian, P. W. (2011). Educational research: Competencies for analysis and applications. New Jersey: Pearson Education, Inc.

Glickman, C. D., Gordon, S. P., \& Ross-Gordon, J. M. (2013). The basic guide to supervision and instructional leadership (3rd ed.). Pearson Education, Inc.

Gosling, P., \& Noordam, B. (2011). Mastering your PhD: survival and success in the doctoral years and beyond. Heidelberg: Springer. https://doi.org/10.1007/978-3-642-15847-6

Green, J. L. (2016). Improving graduate students' satisfaction with academic advising (Doctoral dissertation). Retrieved from Proquest database UMI number 1800286751.

Higher Education. (2017, April 16). Abu Dhabi Education Council (ADEC). Retrieved from https://www.adec.ac.ae/en/education/highereducation/pages/default.aspx

Ho, J. C., Wong, P. T., \& Wong, L. C. (2010). What helps and what hinders thesis completion: A critical incident 
study. International Journal of Existential Psychology and Psychotherapy, 3(2), 117-131.

Ibrahim, A. (2018). Directive, collaborative, or non-directive? Thesis supervision approaches in the United Arab Emirates. Issues in Educational Research, 28(3), 679-700. Retrieved from http://www.iier.org.au/iier28/ibrahim.pdf

Ismail, A., Jui, M. K., Sham, F. M., Faqih, \& Abdullah, N. (2015). Effect of mentoring program on mentees' academic performance from an islamic Perspective. Islamiyyat, 37(1), 29-38. https://doi.org/10.17576/islamiyyat-2015-3701-03

Johnson, W. B. (2016). On being a mentor: A guide for higher education faculty. New York: Routledge. https://doi.org/10.4324/9781315669120

Kessinger, T. A. (2011). Efforts toward educational reform in the United States since 1958: A review of seven major initiatives. American Educational History Journal, 38(1/2), 263.

Koirala, M. P. (2011). Existentialism in education. Academic voices: A Multidisciplinary Journal, 1, 39-44. https://doi.org/10.3126/av.v1i0.5309

Lee, A. M. (2007). Developing effective supervisors: Concepts of research supervision. South African Journal of Higher Education, 21(4), 680-693. https://doi.org/10.4314/sajhe.v21i4.25690

Lee, A. M. (2008). How are doctoral students supervised? Concepts of doctoral research supervision. Studies in Higher Education, 33(3), 267-281. https://doi.org/10.1080/03075070802049202

McAlpine, L., \& McKinnon, M. (2013). Supervision-the most variable of variables: Student perspectives. Studies in Continuing Education, 35(3), 265-280. https://doi.org/10.1080/0158037X.2012.746227

McCallin, A., \& Nayar, S. (2012). Postgraduate research supervision: A critical review of current practice. Teaching in Higher Education, 17(1), 63-74. https://doi.org/10.1080/13562517.2011.590979

Parker-Jenkins, M. (2018). Mind the gap: developing the roles, expectations and boundaries in the doctoral supervisor-supervisee relationship. Studies in Higher Education, 43(1), 57-71. https://doi.org/10.1080/03075079.2016.1153622

Raven, B. H. (2008). The bases of power and the power/interaction model of interpersonal influence. Analyses of Social Issues and Public Policy, 8(1), 1-22. https://doi.org/10.1111/j.1530-2415.2008.00159.x

Shatnawi, N. M. (2006). Administrative problems that graduate students encounter in Umm Al-Qura University. Journal of Education and Psychology, 18(2), 370-408.

Wengraf, T. (2001). Models of research design and their application to semi-structured depth interviewing. Qualitative Research Interviewing. London: SAGE Publications. https://doi.org/10.4135/9781849209717.n3

Wisker, G. (2012). The good supervisor (2nd ed.). Basingstoke: Palgrave Macmillan. https://doi.org/10.1007/978-1-137-02423-7

Ylijoki, O. (2001). Master's Thesis Writing from a Narrative Approach. Studies in Higher Education, 26(1), 21-34. https://doi.org/10.1080/03075070020030698

\section{Appendix A}

\section{Survey Questions}

Dear Participant:

I aim to investigate the relationship between master's and $\mathrm{PhD}$ graduates' levels of satisfaction with their supervision. You only need 10 to 15 minutes to complete the questionnaire. All the information provided will remain confidential and anonymous. Please do not include your name or any other identifying information. Completion and return of the questionnaire will indicate your willingness to participate in this study.

Please do not hesitate to contact me if you need clarifications or have any questions.

Thank you for your contribution. 
Dalal Al Dosari,

Master's Candidate

Mobile: 0502004227.

Email:200719912@uaeu.ac.ae

Graduate students' satisfaction with their supervisors' approaches:

A study of one university in the UAE

Directions: Please check one choice for each of the following:

Section 1: Demographic data

$\begin{array}{ccc}\text { Gender: } & \text { Level of education: } & \text { Status: } \\ \text { Male } & \text { Master } & \text { Graduated (finished the } \\ \text { Female } & \text { DBA } & \text { thesis/dissertation) } \\ & \text { PhD } & \text { About to finish the } \\ & & \text { thesis/dissertation }\end{array}$

\section{College:}

Food and Agriculture

Engineering

Medicine and Health

\author{
Business and Economics \\ Humanities and Social Sciences \\ Information Technology
}

Law

Science

Education

\section{Section 2: Supervisory practices}

Directions: Below are sets of four sentences. Check which statement best describes your thesis/dissertation supervisor. If you worked with more than one supervisor, consider your latest supervisor only. You may choose only one of the four options.

\section{1: Selecting the research topic:}

My supervisor directed me to a certain topic to study.

My supervisor gave me some ideas for topics and asked me to select one to study.

My supervisor and I discussed different topics and we decided together to study one.

My supervisor gave me complete freedom to select the topic.

\section{How satisfied are you with the supervisor's behavior in "selecting the research topic"?}

$\begin{array}{llllll}\begin{array}{l}\text { Totally } \\ \text { satisfied }\end{array} & \text { Satisfied } & \begin{array}{l}\text { Somewhat } \\ \text { satisfied }\end{array} & \begin{array}{l}\text { Somewhat } \\ \text { unsatisfied }\end{array} & \text { Not satisfied } & \begin{array}{l}\text { Not satisfied at } \\ \text { all } \\ 6\end{array} \\ 6 & 4 & 3 & 2 & 1\end{array}$

\section{2: Formulating the research problem:}

My supervisor understood the problem in a certain way, and I had to follow his/her understanding.

My supervisor showed me different ways to frame the problem and I selected one. 
My supervisor and I reached an agreement on how to formulate the problem.

My supervisor gave me complete freedom to frame the problem.

\section{How satisfied are you with the supervisor's behavior in "formulating the research problem"?}

$\begin{array}{llllll}\begin{array}{l}\text { Totally } \\ \text { satisfied }\end{array} & \text { Satisfied } & \begin{array}{l}\text { Somewhat } \\ \text { satisfied }\end{array} & \begin{array}{l}\text { Somewhat } \\ \text { unsatisfied }\end{array} & \text { Not satisfied } & \begin{array}{l}\text { Not satisfied at } \\ \text { all }\end{array} \\ 6 & 5 & 4 & 3 & 2 & 1\end{array}$
6 5 4 3

\section{3: Framing the literature review:}

My supervisor had a view on the literature and I had to cope with it.

My supervisor suggested different ways to frame the literature and I made my selection.

My supervisor and I discussed different ways to frame the literature and we decided together to adopt one.

My supervisor gave me complete freedom to frame the literature as I understood it.

How satisfied are you with the supervisor's behavior in "framing the literature"?

$\begin{array}{llllll}\begin{array}{l}\text { Totally } \\ \text { satisfied }\end{array} & \text { Satisfied } & \begin{array}{l}\text { Somewhat } \\ \text { satisfied }\end{array} & \begin{array}{l}\text { Somewhat } \\ \text { unsatisfied }\end{array} & \text { Not satisfied } & \begin{array}{l}\text { Not satisfied at } \\ \text { all } \\ 6\end{array} \\ 6 & 4 & 3 & 2 & 1\end{array}$

\section{4: Deciding on the research methodology:}

My supervisor preferred a certain methodology and I had to use it.

My supervisor told me about the different research methodologies and asked me to select one to use.

My supervisor and I reached an agreement on the research methodology.

My supervisor gave me the freedom to select the methodology of my study.

$\begin{aligned} & \text { How satisfied are you with the supervisor's behavior in "deciding on the research } \\ & \text { methodology"? }\end{aligned}$
$\begin{aligned} & \text { Totally } \\ & \text { satisfied }\end{aligned}$
$\begin{array}{llllll}\text { Satisfied } & \begin{array}{l}\text { Somewhat } \\ \text { satisfied }\end{array} & \begin{array}{l}\text { Somewhat } \\ \text { unsatisfied }\end{array} & \text { Not satisfied } & \begin{array}{l}\text { Not satisfied at } \\ \text { all }\end{array} \\ 6 & 5 & 4 & 3 & 2 & 1\end{array}$

\section{5: Providing feedback:}

My supervisor gave me direct feedback and I had to do as he/she directed.

My supervisor gave me a lot of feedback and I was allowed to select the ones I saw suitable.

My supervisor gave me enough freedom to discuss his/her feedback and we agreed on the things I should change.

My supervisor did not give me direct feedback. I felt that I was the one who led the feedback process and $\mathrm{s} / \mathrm{he}$ was supportive of this attitude. 
How satisfied are you with the supervisor's behavior in "providing feedback"?

$\begin{array}{llllll}\begin{array}{l}\text { Totally } \\ \text { satisfied }\end{array} & \text { Satisfied } & \begin{array}{l}\text { Somewhat } \\ \text { satisfied }\end{array} & \begin{array}{l}\text { Somewhat } \\ \text { unsatisfied }\end{array} & \text { Not satisfied } & \begin{array}{l}\text { Not satisfied at } \\ \text { all }\end{array} \\ 6 & 5 & 4 & 3 & 2 & 1\end{array}$

\section{6: Writing the discussion chapter:}

My supervisor directed me to produce the discussion chapter in a specific way and I had no choice but to agree with his/her requirements.

My supervisor gave me some alternatives for writing the discussion chapter and I selected one to follow.

My supervisor and I reached an agreement on the way of writing the discussion chapter and s/he accepted some of my ideas.

My supervisor gave me complete freedom to write the discussion chapter as in my way.

How satisfied are you with the supervisor's behavior in "writing the discussion chapter"?

$\begin{array}{llllll}\begin{array}{l}\text { Totally } \\ \text { satisfied }\end{array} & \text { Satisfied } & \begin{array}{l}\text { Somewhat } \\ \text { satisfied }\end{array} & \begin{array}{l}\text { Somewhat } \\ \text { unsatisfied }\end{array} & \text { Not satisfied } & \begin{array}{l}\text { Not satisfied at } \\ \text { all }\end{array} \\ 6 & 5 & 4 & 3 & 2 & 1\end{array}$

\section{7: Overall, during the writing of my thesis/dissertation, I believe:}

My supervisor used the directive approach: giving me specific ideas and steps to follow.

My supervisor used the alternatives approach: giving me options and asking me to select from them.

My supervisor used the collaborative approach: giving me complete freedom to share my ideas and we agreed together on what was to be done.

My supervisor used the non-directive approach: giving me complete freedom to write the thesis/dissertation as I liked.

\section{In general, how satisfied are you with your supervisor's approach?}

$\begin{array}{llllll}\begin{array}{l}\text { Totally } \\ \text { satisfied }\end{array} & \text { Satisfied } & \begin{array}{l}\text { Somewhat } \\ \text { satisfied }\end{array} & \begin{array}{l}\text { Somewhat } \\ \text { unsatisfied }\end{array} & \text { Not satisfied } & \begin{array}{l}\text { Not satisfied at } \\ \text { all }\end{array} \\ 6 & 5 & 4 & 3 & 2 & 1\end{array}$

Please clarify any points from the above or add any comments on the way your supervisor worked with you.

If you are willing to participate in an interview regarding the same topic, please provide your email address (optional): 


\section{Appendix B}

\section{Semi-structured Interview Questions}

\section{Graduate students' satisfaction with their supervisors' approaches:}

A study on one university in the UAE

(Semi-structured Interview)

Demographic data:

$\begin{array}{cc}\text { Gender: } & \text { Level of education: } \\ \text { Male } & \text { Master } \\ \text { Female } & \text { DBA } \\ & \mathrm{PhD}\end{array}$

\author{
Status: \\ Graduated (finished the \\ thesis/dissertation)
}

About to finish the thesis/dissertation

\section{College:}

Food and Agriculture

Business and Economics

Law

Engineering

Humanities and Social Sciences

Science

Medicine and Health

Information Technology

Education

\section{Supervisory practices:}

1 - How did you select your thesis topic?

\section{Sub-questions:}

Did your supervisor direct you to a certain topic? Or

Did your supervisor give you some ideas for topics and you selected one? Or

Did you discuss different topics with your supervisor and decide together to study one? Or

Are you the one who selected the topic alone? (Your supervisor gave you the complete freedom to do so.)

How satisfied are you with your supervisor's behavior in "selecting the research topic"?

\section{2 - How did you formulate the research problem?}

\section{Sub-questions:}

Did your supervisor direct you to a certain way of formulating the problem and you had to follow it? Or

Did your supervisor show you different ways of formulating the problem and you selected one way to write it? Or

Did you reach an agreement with your supervisor on how to formulate the problem? Or

Did your supervisor give you the freedom to formulate the problem the way you wanted to?

How satisfied are you with your supervisor's behavior in "formulating the research problem"?

\section{3 - How did you frame the literature review?}


Did your supervisor have a view on the literature that you had to cope with? Or

Did your supervisor suggest different ways to frame the literature and you made your selection from among them? Or

Did your supervisor and you discuss different ways to frame the literature and decide together to adopt one? Or

Did your supervisor give you complete freedom to frame the literature as you understood it?

How satisfied are you with your supervisor's behavior in "framing the literature"?

\section{4 - How did you decide on the research methodology?}

\section{Sub-questions:}

Did your supervisor prefer a certain methodology that you had to use? Or

Did your supervisor tell you about the different research methodologies and ask you to select one to use? Or

Did your supervisor and you arrive at an agreement on the research methodology? Or

Did your supervisor give you the freedom to select the methodology for your study?

How satisfied are you with your supervisor's behavior in "deciding on the research methodology"?

\section{5 - How did your supervisor provide you with feedback?}

\section{Sub-questions:}

Did your supervisor give you direct feedback and you had to do as he/she directed? Or

Did your supervisor give you multiple rounds of feedback that you were allowed to choose from, to select the ones you saw suitable? Or

Did your supervisor give you enough freedom to discuss his/her feedback and you agreed on the things you should change? Or

Are you the one who led the feedback process and your supervisor did not give you direct feedback?

How satisfied are you with your supervisor's behavior in "providing feedback"?

\section{6 - How did you write the discussion chapter?}

\section{Sub-questions:}

Did your supervisor direct you to produce the discussion chapter and you had to follow his directions? Or

Did your supervisor give you some alternatives for writing the discussion chapter and you selected one to follow from among them? Or

Did your supervisor and you arrive at an agreement on the way of writing the discussion chapter? Or

Did your supervisor give you complete freedom to write the discussion chapter in your way?

How satisfied are you with your supervisor's behavior in "writing the discussion chapter"?

7 - Overall, during the writing of your thesis/dissertation, what approach did your supervisor use?

Sub-questions: Is it...? 
Directive approach: giving you specific ideas and steps to follow.

Alternatives approach: giving you options and asking you to select from them.

Collaborative approach: giving you complete freedom to share your ideas and together decide on what was to be done.

Non-directive approach: giving you complete freedom to write the thesis/dissertation as you like.

In general, how satisfied are you with your supervisor's approach?

\section{Appendix C}

Research Ethics Approval

\section{Social Sciences Research Ethics Committee} -Approval-

$$
\begin{aligned}
& \text { Proposal number: } \\
& \text { Tite of Project: }
\end{aligned}
$$

ERS_2017_5534

The Relationship between Graduate Student Satisfaction and Supervisor Interpersonal approach at one University in the United Arab Emirates

$\mathrm{Pl}:$

Co-PI:

Dalal Mohammed Al Dosari
The above proposal has been reviewed by:

Q one member of the Social Sciences REC

$\square$ two members of the Social Sciences REC

And the decision is:

\Favourable

$\square$ Favourable with Additional Conditions

$\square$ Provisional Opinion

$\square$ Unfavourable Opinion

$\square$ No Opinion (Proportionate Review* only)

Reason:

After evaluating this proposal, we see no major ethical concems. Therefore, the proposal is approved for the duration of the research study.

\begin{tabular}{lll} 
Name & Clara Morgan & \\
\cline { 2 - 3 } (Chair or designee): & & \\
& & March 14, 2017 \\
\hline Signature & Date
\end{tabular}




\section{2| Page}

The decisions available to the Committee are defined as follows:

"Favourable with standard conditions" means that the study has ethical approval to proceed, as long as local management approval is in place prior to the study starting

"Favourable with Additional Conditions" means that the study has ethical approval in principle but there are certain issues, which need to be addressed prior to the study starting such as a minor change to participant documentation. It is the responsibility of the Principal Investigator to ensure that additional conditions are met.

"Provisional 0pinion" means that there are more substantial changes, which need to be made before the study starts. These changes would require further ethical review on the basis of which a favourable or unfavourable opinion would be given by the Ethics Committee.

Unfavourable Opinion_means that the study does not have ethical approval to proceed and a further application would need to be submitted should the applicant choose to proceed with the study. Advice and guidance will be provided by the Committee setting out the reasons for their decision and suggesting changes which would mean that a favourable opinion on resubmission would be more likely. For applications processed through the Proportionate Review* Service an unfavourable opinion is only given where the ap plication is of such poor quality that it is probable that an unfavourable opinion would be given if it were to be reviewed at a full meeting.

No Opinion (Proportionate Review* only), means that the Proportionate Review subcommittee ( 3 members) have deemed that the proposed study does have material ethical issues and will therefore need to be reviewed by a full committee.

"The aim of proportionate review is for studies which present minimal risk or burden for participants to be reviewed by a proportionate review sub-committee within 14 days of receipt of a valid application.

\section{Copyrights}

Copyright for this article is retained by the author(s), with first publication rights granted to the journal.

This is an open-access article distributed under the terms and conditions of the Creative Commons Attribution license (http://creativecommons.org/licenses/by/4.0/). 